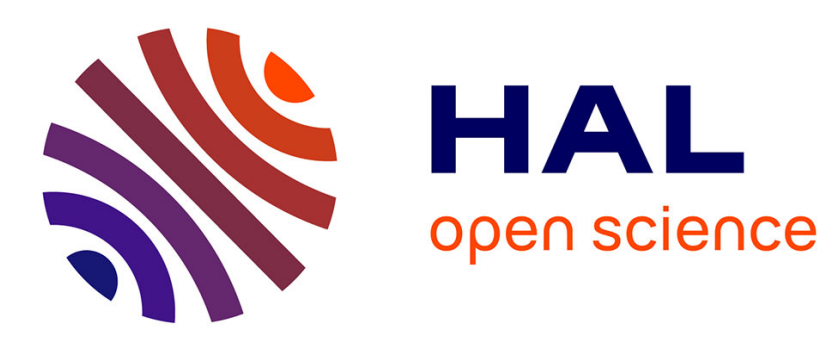

\title{
Can labelling policies do more harm than good? An analysis applied to environmental labelling schemes
}

Douadia Bougherara, Gilles Grolleau, Luc Thiébaut

\section{To cite this version:}

Douadia Bougherara, Gilles Grolleau, Luc Thiébaut. Can labelling policies do more harm than good? An analysis applied to environmental labelling schemes. European Journal of Law and Economics, 2005, 19 (1), pp.5-16. 10.1007/s10657-005-5273-6 . hal-01939936

\section{HAL Id: hal-01939936 https://hal.science/hal-01939936}

Submitted on 29 Nov 2018

HAL is a multi-disciplinary open access archive for the deposit and dissemination of scientific research documents, whether they are published or not. The documents may come from teaching and research institutions in France or abroad, or from public or private research centers.
L'archive ouverte pluridisciplinaire HAL, est destinée au dépôt et à la diffusion de documents scientifiques de niveau recherche, publiés ou non, émanant des établissements d'enseignement et de recherche français ou étrangers, des laboratoires publics ou privés.

$$
\text { Copyright }
$$


Bougherara D., Grolleau G. and L. Thiébaut, 2005, Can Labelling Policies do More Harm Than Good ? An Analysis Applied to Environmental Labelling Schemes, European Journal of Law and Economics, 19:5-16.

\title{
Can Labelling Policies Do More Harm Than Good? An Analysis Applied to Environmental Labelling Schemes ${ }^{1}$
}

\author{
Douadia Bougherara \\ Gilles Grolleau \\ Luc Thiébaut
}

\begin{abstract}
In certain plausible circumstances, the introduction of labelling schemes can lead to adverse effects. In the case of ecolabelling, the adverse effects are an environmental degradation rather than an environmental improvement. To take into account the environmental sensitiveness or responsiveness of consumers, we introduce the concept of environmental elasticity which enables us to classify goods. In a basic analytical model, we describe the conditions under which different outcomes - overall impacts of change in environmental quality due to environmental labelling - arise after the introduction of an ecolabelling scheme. We show that an ecolabelling scheme can lead to an increase in purchases of environmentally sustainable products. The net effect on the environment can be worse than the initial situation without ecolabelling, because the environmental unit improvement is compensated by an overconsumption. We suggest several tests to detect this potential perverse effect, some policy implications to avoid it and stress the need for further research.
\end{abstract}

Key words: Labelling; Ecolabelling; Policy; Environmental elasticity.

JEL Classification Numbers: D11, L15, Q28.

\footnotetext{
${ }^{1}$ We are indebted to Carl Gaigné for his numerous detailed comments and constant encouragement. We greatly appreciate the comments of the three referees. We are also grateful to Gabriel Lecat, Pascale Lofredi, Julie A. Caswell and Naoufel Mzoughi for stimulating conversations. The usual disclaimer applies.
} 


\title{
Can Labelling Policies Do More Harm Than Good? An Analysis Applied to Environmental Labelling Schemes
}

\begin{abstract}
In certain plausible circumstances, the introduction of labelling schemes can lead to adverse effects. In the case of ecolabelling, the adverse effects are an environmental degradation rather than an environmental improvement. To take into account the environmental sensitiveness or responsiveness of consumers, we introduce the concept of environmental elasticity which enables us to classify goods. In a basic analytical model, we describe the conditions under which different outcomes - overall impacts of change in environmental quality due to environmental labelling - arise after the introduction of an ecolabelling scheme. We show that an ecolabelling scheme can lead to an increase in purchases of environmentally sustainable products. The net effect on the environment can be worse than the initial situation without ecolabelling, because the environmental unit improvement is compensated by an overconsumption. We suggest several tests to detect this potential perverse effect, some policy implications to avoid it and stress the need for further research.
\end{abstract}

Key words: Labelling; Ecolabelling; Policy; Environmental elasticity..

JEL Classification Numbers: D11, L15, Q28. 


\section{Can Labelling Policies Do More Harm Than Good? An Analysis Applied to Environmental Labelling Schemes}

"I can sum up my notion of good practice in three injunctions.

1. Keep it simple.

2. Get it right.

3. Make it plausible."

Robert Solow (2001)

\section{Introduction and review of the literature}

The credible labelling of products is frequently considered as an accurate information-based policy to promote informed choices, notably in the case of credence products ${ }^{2}$ such as light products, lownicotine cigarettes, low-alcohol beers or protective solar filters. Following the same line, the ecolabelling of products is frequently presented as an appropriate, though partial policy tool to regulate environmental problems ${ }^{3}$. It is expected that ecolabels, by providing environmental information, will encourage consumers to discriminate between products and purchase products that have fewer environmental impacts than competing alternatives. Producers will have a greater incentive to manufacture environmentally friendly products. From a public point of view, the net expected effect will be an improvement in overall environmental quality (Morris and Scarlett, 1997).

Similarly to other papers (Mattoo and Singh, 1994; Dosi and Moretto, 2001), we argue that ecolabelling schemes could, in certain plausible circumstances, lead to an adverse effect on the environment. This paper differs from the previous ones by the source of the perverse effect considered and the analytical framework. Mattoo and Singh (1994) distinguish between concerned and unconcerned consumers about environmental problems. Ecolabelling may stimulate concern for the environment and increase the demand for environmentally friendly products. In certain plausible cases, they show that the differentiation of products due to ecolabelling may lead to increased sales of products made by environmentally friendly and environmentally unfriendly methods. Dosi and Moretto (2001) consider the effects of an ecolabelling scheme on the incentives of firms to innovate and to invest in green technology. They argue that an ecolabelling scheme could increase investment in the conventional

\footnotetext{
${ }^{2}$ Credence goods are goods for which consumers cannot determine quality either through search, inspection or experience. Consumers cannot determine quality even after they buy and consume the product. Frequently for these goods, one must rely on a third party (third party certification or governmental regulations) to provide credible information to the consumer whether the product is high quality or not.

${ }^{3}$ To make the exposition clear, we deal especially with ecolabelling, but the approach can be easily generalized to numerous other applications. Anyway, we deal with labelling schemes indicating to consumers attributes of the product having less negative impacts on diverse targets like the environment or health.
} 
polluting technology even if green consumption is stimulated by the ecolabelling scheme. It is the case if there are image spillovers, i.e. if the ecolabel projects a positive image not only on the environmentally friendly product but also on the conventional product.

This paper argues that the introduction of an ecolabelling scheme may encourage people to consume more, and in certain cases, the overall effect on the environment may be worse than the initial situation, i.e. the situation without ecolabelling scheme. A simple example will make clear the intuitive rationale for such a result. Say the market for two goods $X$ and $Y$ is in equilibrium respectively at prices $p_{x}=10$ and $p_{y}=5$ with quantities $x=10$ and $y=120$ for an income $R=700$. For each good, one unit has a negative impact, $i_{x}=1$ and $i_{y}=0,2$. The overall environmental impact of all the products is then $34(10 \times 1+120 \times 0,2)$. Now ecolabelling is introduced for the good $X$, which means that this product with fewer environmental impacts is launched at the same price as before. Its environmental impact is only of $i_{x}=0,8$. Let us further assume that the introduction of environmentally friendly products stops consumers feeling guilty and generates an increase in the consumption of the good $X$. If this increase exceeds a certain level, in our example 15 units, the overall impact on the environment will be greater after the introduction of the ecolabelling scheme. The increase in the quantity of the good $X$ will lead to a decrease of the quantity of good $Y$. For a constant income, the quantity of good $Y$ is now $60((700-10 \times 40) / 5)$. Indeed, if people consume now 40 units of good $X$ and 60 units of good $Y$, then the overall impact is worse, i.e. $44(40 \times 0,8+60 \times 0,2)$ which is superior to the initial level, i.e. 34 . The same reasoning applies for an increase in the price of $X$. Although this example seems rather diagrammatic, these potential perverse effects correspond to a real concern of practitioners and policy-makers (Byron, 2001, p.6; European Environmental Bureau, 2003, p.11 ${ }^{4}$. In other words, the environmental improvement per unit of product is cancelled by a consumption increase. In our reasoning, consumers care about the environmental impact per product unit and do not compute the overall impact of their consumption ${ }^{5}$. Manufacturers encourage consumers to buy the highest quantity of their products in order to maximise their profits. Consequently, manufacturers emphasise the individual qualities of their products, notably

\footnotetext{
${ }^{4}$ Byron, Neil, 2001, Environmental Certification and Labelling, The Common Property Resource Digest, 56, p.5-6. European Environmental Bureau, 2003, An Environmental NGO Vision Paper Towards a European Integrated Product Policy, 13p, March 2003.

${ }^{5}$ Note that we do not consider the overall environmental impact from the consumer viewpoint, but from the state viewpoint, the state wanting to minimize the overall environmental impact. Indeed, we only assume that the consumer is interested by minimizing the impact per product unit consumed, regardless of the individual and global overall impacts. Consequently, the consumer only takes into account the environmental impact per unit and does not compute either the aggregated impact of his total consumption or the overall impact resulting from all consumers' decisions.
} 
in their advertising. They have little incentives to highlight the potentially adverse effects of the total consumption ${ }^{6}$.

The remainder of the paper is organised as follows: In the next section, the concept of environmental elasticity is introduced and some empirical tests in order to characterise the properties of goods are suggested. In section III, we examine the possible outcomes in terms of environmental quality after the introduction of an ecolabelling scheme in a basic model. We identify the conditions under which potentially 'perverse effect' of introducing ecolabelling schemes can arise. Section IV outlines the relevance of the results for policy makers. Section V provides some concluding remarks, notably by stressing numerous potential extensions of this paper.

\section{Environmental Elasticity of Demand and the Classification of Goods}

The environmental elasticity $\varepsilon$ of demand for a given product measures the responsiveness of demand for this product to a given change in the environmental impact $i$ of the product, or in the level of pollution, due to the production of the good. Using the conventional equation in the case of a continuous and derivable function, the environmental elasticity $\mathcal{E}$ is given by:

$$
\varepsilon=\frac{\frac{d x}{x}}{\frac{d i_{x}}{i_{x}}}
$$

\footnotetext{
${ }^{6}$ Several studies stress the potentially perverse effects resulting from diverse labelling schemes. For example, a French report of the National Council of Consumption (Rapport du Conseil national de la Consommation sur les produits cosmétiques de protection solaire, 2000) explains that the labelling of higher solar protection makes "consumers think they are well protected, notably products labeled with high Sunburn Protection Factor (...). Consumers tend to go out in the sun longer and adopt a risky behavior for their health".

We find the same line of reasoning for nutritional and functional claims, where the labelling of a specific improvement can lead to an over-consumption (See for example: Parliamentary Assembly of the European Union, 2002, Functional food : serving the interests of the consumer on the food industry? and European Commission, 2001, Discussion Paper on Nutrition Claims and Functional Claims). Lastly, according to Dr Pellae, "a study of Pr Apfelbaum has showed that people eat twice more because the products are light. When certain people read a claim "light" on a foodstuff, they perceive it like a miraculous product to lose weight (...)." (www.doctissimo.fr/html/nutrition/mag 2002/mag0607/ nu 5559 faux sucres danger itw.htm).

Another meaningful and well documented example relates to cigarettes labelled as "safer". Several studies show that these "safer" cigarettes frequently do more harm than good. According to a literature review (The Cigarettes Companies and "Safer" Cigarettes - A Long History of Exploiting Consumers Health Concerns to Keep Them Smoking, 2000, http://tobaccofreekids.org/research/factsheets/), "soon after the cigarette companies began selling low tar and nicotine cigarettes, it became clear the smokers that switched to these "light" brands were compensating for the lower nicotine levels by adopting new ways of smoking the cigarettes so they would still consume the same amounts of nicotine as they would with regular brands."
} 
$d x$ corresponds to the variation in the quantity exchanged. For a discrete function, it is the difference between the quantity exchanged of environmentally friendly products $\left(x_{e}\right)$ and the quantity exchanged of conventional products $\left(x_{c}\right)$, before the introduction of the ecolabelling scheme $\left(\Delta x=x_{e}-x_{c}\right)$.

$d i_{x}$ corresponds to a small change in the environmental quality of the products. For a discrete function, it is the difference between the environmental impact (or pollution) generated by the environmentally friendly product $\left(i_{x}^{e}\right)$ and the environmental impact generated by the conventional product $\left(i_{x}^{c}\right)$ $\left(\Delta i_{x}=i_{x}^{e}-i_{x}^{c}\right)$. Note that $\Delta i_{x}<0$ because we postulate an environmental improvement by diminishing the value of $i_{x}$, i.e. $i_{x}^{e}<i_{x}^{c}$.

In our introductive example, the elasticity is negative and its absolute value greater than one, i.e. -15 . In a first approach, we consider that ecolabelling schemes only affect the environmental impacts (and the environmental perception) generated by the product and leaves unchanged the other qualities of the good.

According to the concept of environmental elasticity, we propose an intuitive classification of goods in table 1. For example, we can intuitively suppose that the demand for clothes is not influenced by the environmental qualities of the clothes $(\varepsilon=0)$ while the demand for paper will increase substantially $(|\varepsilon|<1)$ because of the introduction of an environmentally friendly paper, such as recycled paper?

\begin{tabular}{|c|c|c|c|}
\hline \multicolumn{2}{|c|}{ Value of the elasticity } & Demand & Effect of a decrease in the environmental impact $i_{x}$ on the demand $x$ \\
\hline \multirow{3}{*}{$\mathcal{E}<0$} & $\varepsilon<-1$ & elastic & $x$ increases proportionally more than the proportional change in $i_{x}$ \\
\cline { 2 - 5 } & $\varepsilon=-1$ & unit elasticity & $x$ increases proportionally as much as the proportional change in $i_{x}$ \\
\cline { 2 - 5 } & $-1<\varepsilon<0$ & inelastic & $x$ increases proportionally less than the proportional change in $i_{x}$ \\
\hline $\mathcal{E}=0$ & $0<\varepsilon<1$ & perfectly inelastic & No change in the consumed quantity $x$ \\
\hline \multirow{2}{*}{$\varepsilon>0$} & $\varepsilon=1$ & unit elasticity & $x$ decreases proportionally less than the proportional change in $i_{x}$ \\
\cline { 2 - 5 } & $\varepsilon>1$ & elastic & $x$ decreases proportionally more than the proportional change in $i_{x}$ \\
\hline
\end{tabular}

Table 1: Types of goods according to their environmental elasticity ${ }^{8}$

\footnotetext{
${ }^{7}$ Marketing literature uses the concept of salient attributes which are attributes taken into account in the purchase of a good. We could say that generally environmental attributes are not as salient for clothes as they are for paper.

${ }^{8}$ In developed countries, people have a high level of satiation with many purchased products and it is possible to argue that we will not really see significant changes in quantities purchased with most products. However, much of the argumentation developed in this article relies on the presence of obstacles leading people to limit their consumption. If these obstacles disappear (e.g. feeling guilty in the case of unsustainable consumption, fear of diseases related to solar exposition or nicotine level in cigarettes), people can naturally choose to increase their consumption.
} 
The classification of goods according to their environmental elasticity is particularly relevant for policy makers who aim at maximising the efficiency of funds invested in ecolabelling schemes. This point is briefly developed in section IV. An empirical way to determine the environmental elasticity of goods is to realise well-designed surveys to simulate the reaction of consumers to the launch of ecolabeled products. Another way is to exploit data related from products launched for their environmental friendliness. A third way to test this environmental elasticity is to achieve pilot studies in supermarkets by proposing identical products (same price, brand name and other properties) with added environmental qualities. These different ways are neither exhaustive nor mutually exclusive and can be combined to get better results.

\section{The model}

The basic results can be demonstrated in a very simple model. To keep the analysis simple and isolate the main effects, we consider, in a first approach, two goods $X$ and $Y$. Each good leads to an environmental impact per unit, or a level of pollution, respectively $i_{x}$ and $i_{y}$. We consider that good $X$ is awarded an ecolabel, after the adoption of environmental criteria leading to a decrease in $i_{x}$. We assume several restrictive hypotheses: (1) All consumers are equally concerned about the environment. Their preferences are perfectly homogeneous. (2) The perceived change in the environmental performances of the product shapes the quantities demanded. The perceived change corresponds to the real difference in $i_{x}$. We admit that marketing strategies and other parameters can influence the perceived environmental improvement. This effect would be captured by the concept of environmental elasticity. (3) Each consumer perfectly perceives the environmental improvement per unit of product but does not care of the overall environmental impact of his total consumption. This hypothesis means that the consumer does not compare the overall environmental impact or pollution level before and after the introduction of the ecolabelling scheme, but only takes into account the marginal improvement generated by the products. (4) Manufacturing ecofriendly products frequently implies higher production and transaction costs and consequently a price higher than the price of the good before ecolabelling.

Under those hypotheses, we are interested in determining the overall impact $I$ on the environment of the consumption of good $X$ and good $Y$. I is a function of each good's quantity and each good's environmental impact so that we can write: $I=I\left(x, i_{x}, y, i_{y}\right)$. In our model, $i_{y}$ is constant. Thus, $I=I\left(x, i_{x}, y\right)$. The total differential of $I$ is:

$$
d I=\frac{\partial I}{\partial x} d x+\frac{\partial I}{\partial i_{x}} d i_{x}+\frac{\partial I}{\partial y} d y \quad \text { (2) } \quad \text { with } \frac{\partial I}{\partial x}>0, \frac{\partial I}{\partial y}>0 \text { and } \frac{\partial I}{\partial i_{x}}>0
$$


Each demand function $x$ and $y$ is in turn a function of several parameters. As demand functions, $x$ and $y$ are functions of prices and income: $p_{x}, p_{y}$ and $R$. In our model we have an additional variable: the environmental impact per unit, so that not only $x$ and $y$ are a function of respectively $i_{x}$ and $i_{y}$ but the price of good $X$ also depends on $i_{x}$. Demand functions are then: $x=x\left(p_{x}\left(i_{x}\right), p_{y}, R, i_{x}\right)$ and $y=y\left(p_{x}\left(i_{x}\right), p_{y}, R, i_{y}\right)$. In our model, the price of the good $Y, p_{y}$, the income, $R$, and the environmental impact of good $Y, i_{y}$, are constant.

$$
\begin{aligned}
& x=x\left(p_{x}\left(i_{x}\right), i_{x}\right) \\
y= & y\left(p_{x}\left(i_{x}\right)\right)
\end{aligned}
$$

We rewrite $I$ as $I=I\left[x\left(p_{x}\left(i_{x}\right), i_{x}\right), i_{x}, y\left(p_{x}\left(i_{x}\right)\right)\right]$

$$
\begin{aligned}
& (3)=>\quad d x=\frac{\partial x}{\partial p_{x}} d p_{x}+\frac{\partial x}{\partial i_{x}} d i_{x} \quad \text { (5) with } \frac{\partial x}{\partial p_{x}}<0 \text { and }\left\{\begin{array}{l}
\frac{\partial x}{\partial i_{x}}>0 \text { for } \varepsilon<0 \\
\frac{\partial x}{\partial i_{x}}<0 \text { for } \varepsilon>0
\end{array}\right. \\
& \text { (4) }=>\quad d y=\frac{\partial y}{\partial p_{x}} d p_{x} \quad \text { (6) with } \frac{\partial y}{\partial p_{x}}<0 \\
& p_{x}=p_{x}\left(i_{x}\right) \Rightarrow d p_{x}=\frac{\partial p_{x}}{\partial i_{x}} d i_{x} \quad \text { (7) } \quad \text { with } \frac{\partial p_{x}}{\partial i_{x}}<0
\end{aligned}
$$

With (5), (6) and (7) in (2):

$$
\begin{array}{r}
d I=\frac{\partial I}{\partial x}\left[\frac{\partial x}{\partial p_{x}} \frac{\partial p_{x}}{\partial i_{x}} d i_{x}+\frac{\partial x}{\partial i_{x}} d i_{x}\right]+\frac{\partial I}{\partial i_{x}} d i_{x}+\frac{\partial I}{\partial y} \frac{\partial y}{\partial p_{x}} \frac{\partial p_{x}}{\partial i_{x}} d i_{x} \\
d I=\frac{\partial I}{\partial x} \frac{\partial x}{\partial p_{x}} \frac{\partial p_{x}}{\partial i_{x}} d i_{x}+\frac{\partial I}{\partial x} \frac{\partial x}{\partial i_{x}} d i_{x}+\frac{\partial I}{\partial i_{x}} d i_{x}+\frac{\partial I}{\partial y} \frac{\partial y}{\partial p_{x}} \frac{\partial p_{x}}{\partial i_{x}} d i_{x}
\end{array}
$$

Equation (8) shows that the variation in the overall environmental impact due to a decrease in $i_{x}$ $\left(d i_{x}<0\right)$ is an addition of four effects:

\section{A Price Effect}

The first term of equation (8), $\frac{\partial I}{\partial x} \frac{\partial x}{\partial p_{x}} \frac{\partial p_{x}}{\partial i_{x}} d i_{x}$, describes the effect on the overall impact $I$ of a decrease in the quantity of good $X$ due to an increase in its price $p_{x}$ due itself to a 
decrease in its environmental impact per unit, $i_{x}$. The Price Effect is negative, which means a decrease in the overall impact $I$.

\section{An Environmental Elasticity Effect}

The second term of (8), $\frac{\partial I}{\partial x} \frac{\partial x}{\partial i_{x}} d i_{x}$, corresponds to the effect on $I$ of an increase in the quantity of good $X$ due to a decrease in its environmental impact per unit, $i_{x}(\varepsilon<0)$. The Environmental Elasticity Effect is positive when $\mathcal{\varepsilon}<0$ and is negative when $\mathcal{E}>0$.

\section{A Direct Effect}

The third term of (8), $\frac{\partial I}{\partial i_{x}} d i_{x}$, is the direct effect of a decrease in good $X$ 's environmental impact on the overall environmental impact $I$. The Direct Effect is negative.

\section{An Income Share Effect}

The last term of (8), $\frac{\partial I}{\partial y} \frac{\partial y}{\partial p_{x}} \frac{\partial p_{x}}{\partial i_{x}} d i_{x}$, measures the effect on $I$ of a decrease in the demand for good $Y$ due to an increase in the price of good $X$, due itself to a decrease in the environmental impact per unit of good $X, i_{x}$. The Income Share Effect is negative.

A perverse effect on the environment may appear when the Environmental Elasticity Effect is positive and overcomes the other effects (table 2).

\begin{tabular}{|l|c|c|c|}
\hline \multirow{2}{*}{ Effects on I } & \multicolumn{3}{|c|}{ Value of the environmental elasticity } \\
\cline { 2 - 4 } & $\mathcal{E}<0$ & $\mathcal{E}=0$ & $\mathcal{E}>0$ \\
\hline Price Effect & - & - & - \\
\hline Environmental Elasticity Effect & + & 0 & - \\
\hline Direct Effect & - & - & - \\
\hline Revenue Share Effect & - & - & - \\
\hline Total Effect & $?$ & - & - \\
\hline
\end{tabular}

-: Decrease in the overall impact $I, 0$ : No change in $I$, +: Increase in $I$

Table 2: Total effect of a decrease in $i_{x}$ on the overall environmental impact $I$ according to the environmental elasticity 
An important implication is that an adverse effect is more likely to occur if the ecofriendly product can be produced with low cost technologies and if consumers value the environmental improvement per unit of product. Indeed, if reaching the ecolabel criteria is accessible at low costs, the Price Effect and the Income Share Effect are low and give an advantage to the Environmental Elasticity Effect, i.e. a consumption increase due to the environmental improvement. If this consumption increase exceeds a certain level, it will generate an adverse effect on the environment.

We are able to determine the optimal quantities of good $X$ and good $Y$ as consumers are utility maximizers under a budget constraint:

$$
\left\{\begin{array}{l}
\operatorname{Max} U\left(x\left(i_{x}\right), y\right) \\
p_{x} x+p_{y} y=R
\end{array}\right.
$$

We write the first order conditions (Lagrangian function): $\left\{\begin{array}{l}\frac{\partial L}{\partial x}=\frac{\partial U}{\partial x}-\lambda p_{x}=0 \\ \frac{\partial L}{\partial y}=\frac{\partial U}{\partial y}-\lambda p_{y}=0 \\ \frac{\partial L}{\partial x}=-\left(p_{x} x+p_{y} y-R\right)=0\end{array}\right.$

According to the chain rule for derivation, $\frac{\partial U}{\partial i_{x}}=\frac{\partial U}{\partial x} \times \frac{\partial x}{\partial i_{x}}+\frac{\partial U}{\partial y} \times \frac{\partial y}{\partial i_{x}}$. Since $y$ is independent of $i_{x}, \frac{\partial y}{\partial i_{x}}=0 \Rightarrow \frac{\partial U}{\partial i_{x}}=U m_{i}=U m_{x} \times \frac{\partial x}{\partial i_{x}}$

According to the definition of environmental elasticity, $\frac{\partial x}{\partial i_{x}}=\frac{x \mathcal{E}}{i_{x}}$.

$U m_{i}=U m_{x} \times \frac{x^{*} \varepsilon}{i_{x}}$ then: $x^{*}=\frac{U m_{i}}{U m_{x}} \frac{i_{x}}{\varepsilon}$

The budget constraint gives $y^{*}: y^{*}=\frac{R-p_{x} x^{*}}{p_{y}}$ then: $y^{*}=\frac{R}{p_{y}}-\frac{p_{x}}{p_{y}} \times \frac{U m_{i}}{U m_{x}} \times \frac{i_{x}}{\varepsilon}$

$\left(x^{*}, y^{*}\right)$ constitute the optimal quantities of goods.

Let us take a simple case: the price of the good $X$ remains constant. Figure 1 shows the move of the equilibrium quantities after ecolabelling and the consequences on the overall impact on the environment $I$ as a sum of $I_{x}$, the environmental impact due to good $X$ consumption and $I_{y}$, the environmental impact due to good $Y$ consumption. Since $p_{x}$ is constant, the variation in the overall environmental impact is only determined by the Environmental Elasticity Effect and the Direct Effect. An increase in $x$ leads to a decrease in $y$. We consider a decrease in $i_{x}$ after ecolabelling represented by the slope of 
the curve $I_{x}: I_{x}=x i_{x}$. The unit impact decrease leads to a shift downwards. In figure 1, a decrease in $i_{x}$ lead to a decrease in $I$. The introduction of an ecolabel may also lead to an adverse effect if the overall impact after ecolabel introduction is higher than the overall impact before ecolabel introduction (figure 2). The adverse effect, which may appear at the individual level, is still true at an aggregate level. Indeed, there exists a threshold quantity $\tilde{x}$ for which the overall environmental impact is unchanged after the introduction of the ecolabel.

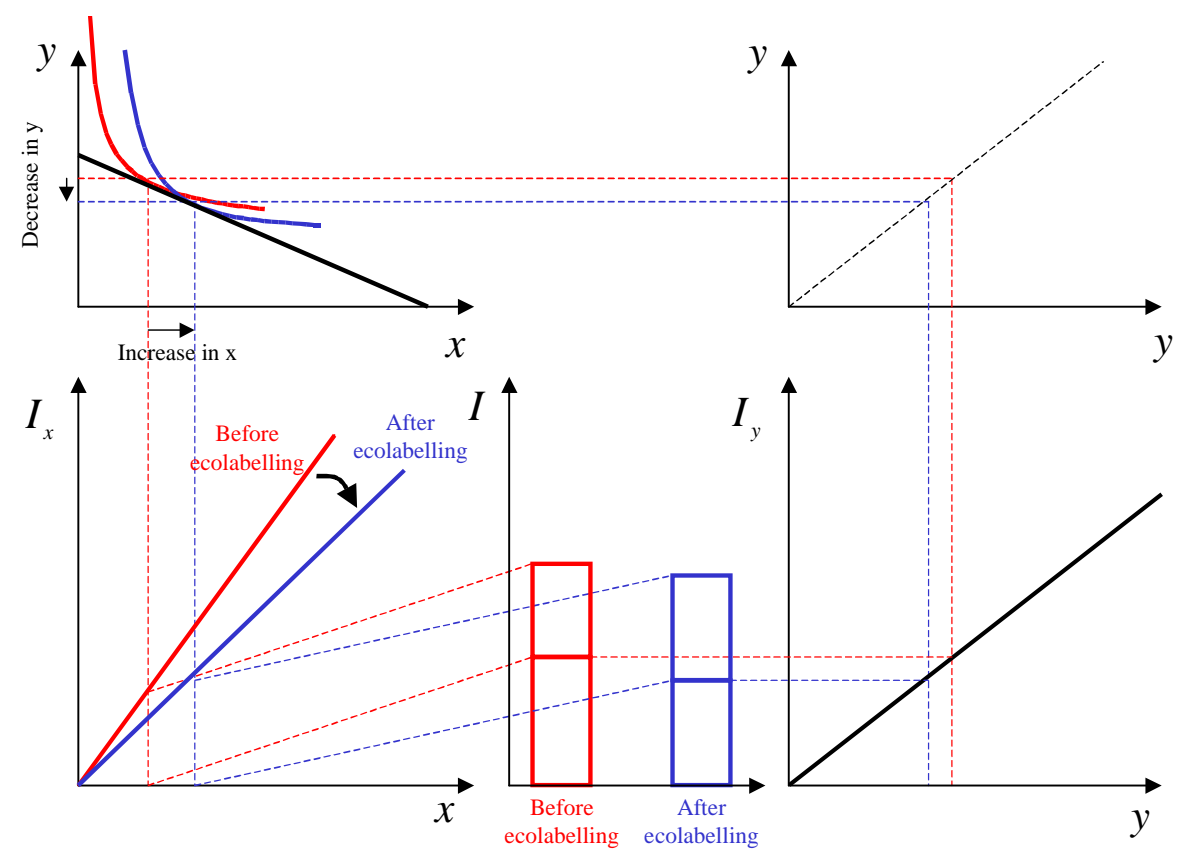

Figure 1: Lower overall environmental impact after ecolabeling for $p_{x}$ constant

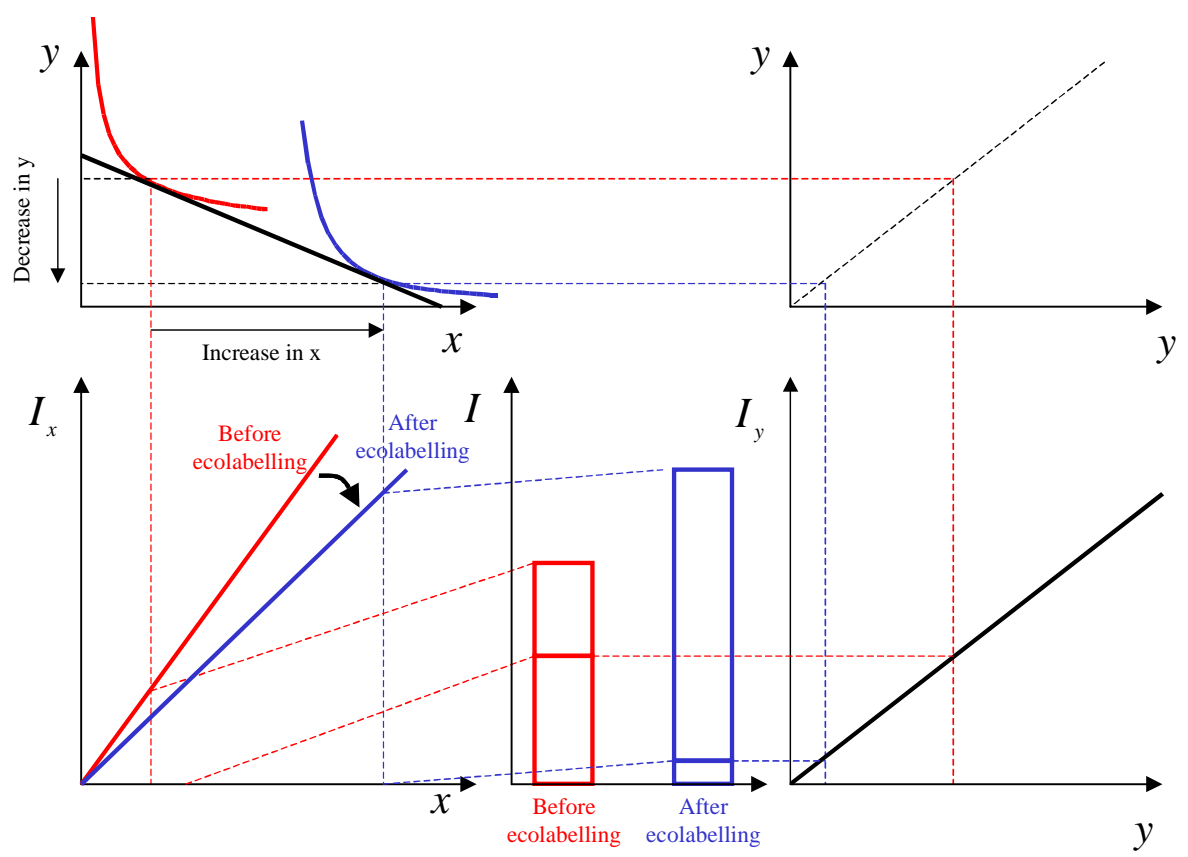

Figure 2: Adverse effect: Higher overall environmental impact after ecolabeling for $p_{x}$ constant 
Let us now consider the case where the price of good $X$ varies. Figure 3 and 4 show the change in the equilibrium quantities after ecolabelling due to the decrease in $i_{x}$ and an increase in $p_{x}$. The variation in the overall environmental impact is determined by the four effects identified in table 2. A decrease in $i_{x}$ after ecolabelling may lead to a lower overall environmental impact as in figure 3 or to a higher overall impact as in figure 4. In figure 4, the introduction of an ecolabel has lead to an adverse effect: the Environmental Elasticity Effect has overcome all the other effects.

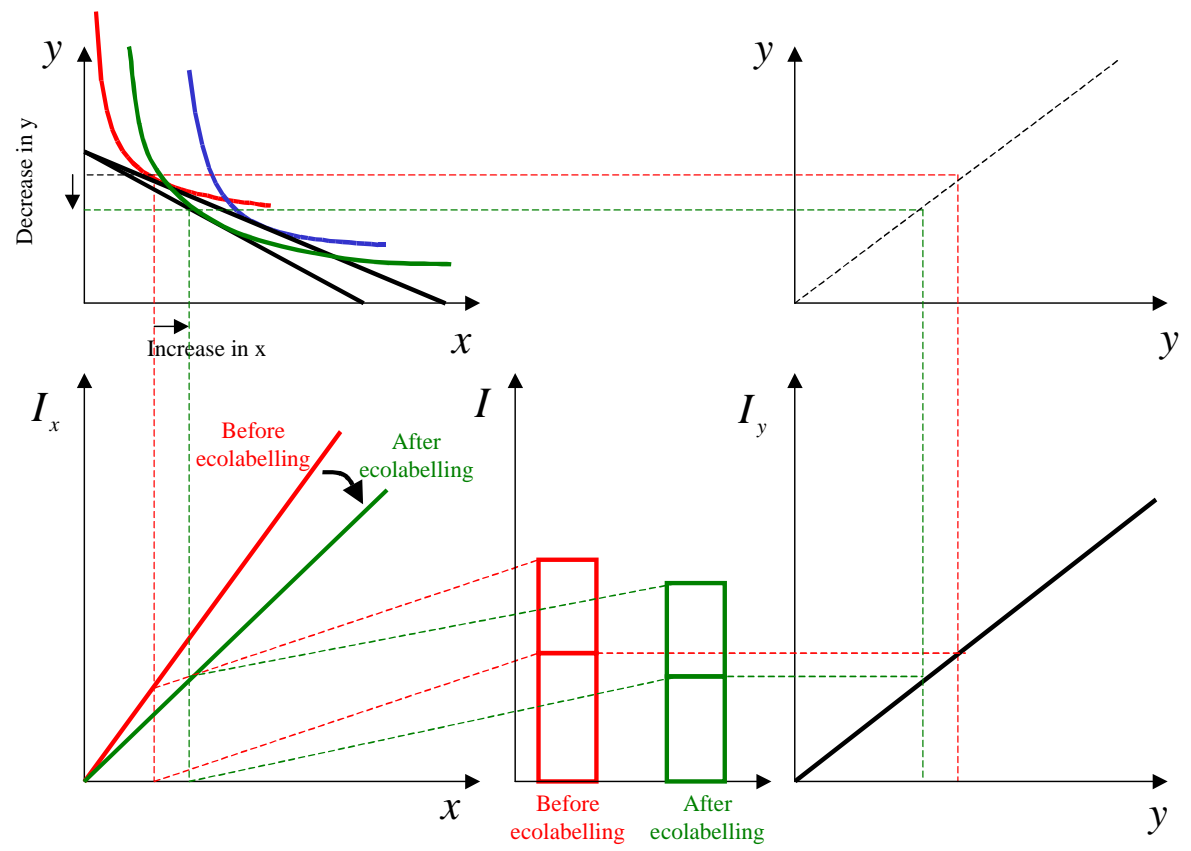

Figure 3: Lower overall environmental impact after ecolabeling when $p_{x}$ increases

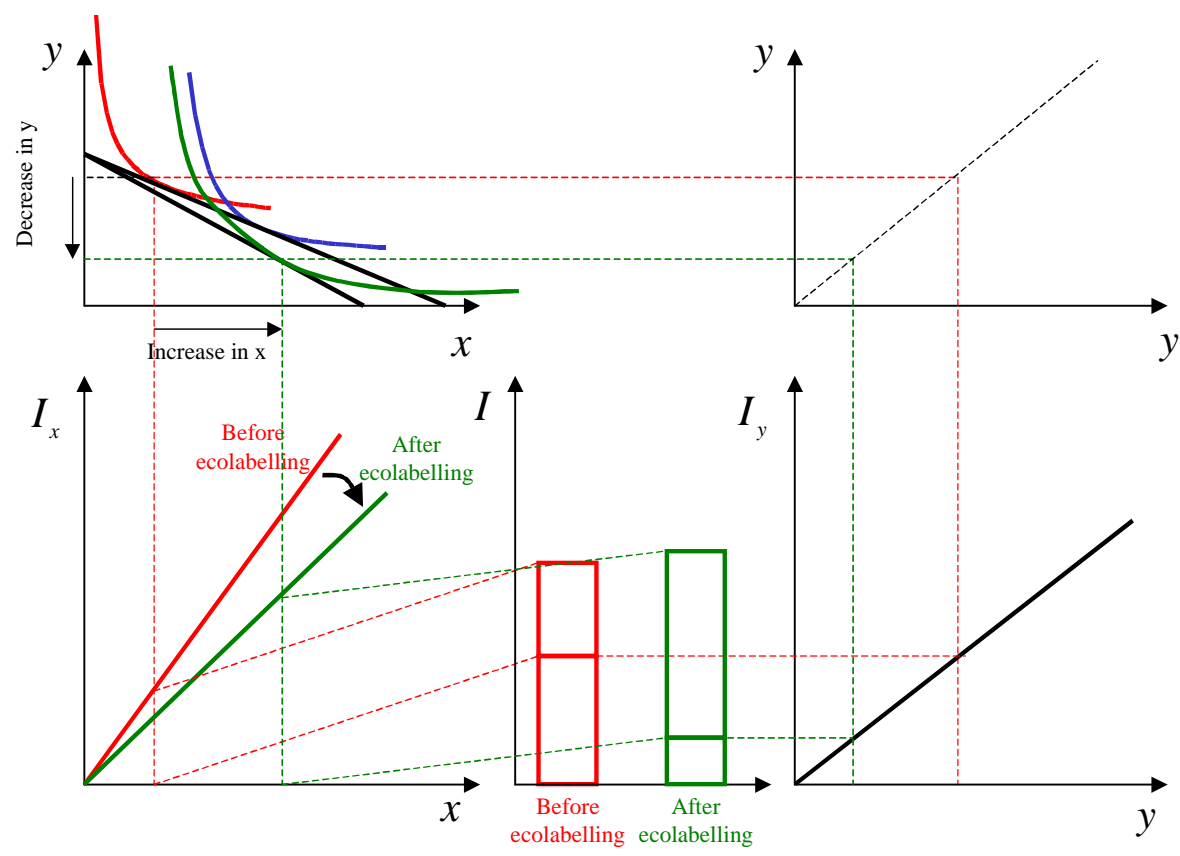

Figure 4: Adverse effect: Higher overall environmental impact after ecolabeling when $p_{x}$ increases 


\section{Policy considerations for introducing ecolabelling schemes}

There are many thousands of product categories available in the marketplace. The costs of generating a specific level of environmental improvement are not the same for all product categories. If we postulate that consumers want to allocate a fraction of their resources to purchase environmentally friendly goods, they will prefer choosing product categories, which will make the most significant improvement to the environment for a given contribution. Indeed, consumers have limited resources and will prefer the most cost-effective solutions. To maximize the environmental effectiveness and the economic efficiency of ecolabels, policy designers need to select the product categories for which ecolabels would make the most significant improvement to the environment. Conversely, profit maximising firms could be interested in awarding environmentally goods characterised by an elasticity leading to a consumption increase. Policy makers include here various kinds of institutions such as governments or environmental associations, which are frequently initiators of ecolabelling schemes. Knowing the environmental elasticity of goods can be useful for policy makers who can select product categories according to the overall expected environmental net effect. Using the empirical tests suggested in the second section can help policy designers to better allocate scarce resources and generate higher environmental improvement, or at least avoid a hidden perverse effect by introducing an ecolabel for an inappropriate product category. Our analysis does not conclude that policy makers have to ban certain product categories, but stresses the need of complementary measures e.g. educating consumers or taxing products to prevent over-consumption in certain cases. Moreover, there is also a temporal dimension in the policy intervention because ecolabelling criteria are regularly reviewed to strengthen the environmental effectiveness of the scheme (Morris et Scarlett, 1996). In a dynamic perspective, we can suppose that meeting ecolabel criteria will be accessible at low cost in the first period. In the following periods, the costs of meeting the updated criteria will generally increase, leading to a stronger price effect. Consequently an adverse effect is more likely to arise in the starting period, where the price effect is weak. That means that regulators have to take into account this timing. Indeed, an intervention is potentially more effective in the first stages of the ecolabel development than in the following ones. In the same line of reasoning, regulators have to take into account the initial level of consumption, which can provide a partial indication on the likelihood of perverse effects

Note that measures aiming at reducing demand potentially conflict with profit maximising strategies of manufacturers. Of course policy makers need to take into account other related effects, which will together shape the quantities consumed and consequently the net environmental effects. For example, as analysed in the section III, a price increase can attenuate the effect due to environmental improvement. By selecting ecolabel criteria accessible at high costs, government can reduce the risk of generating a perverse effect on the environment. However, high costs of complying with the ecolabel criteria may hinder firms' incentives to have their products awarded. This underlines the need to define 
environmental criteria as a trade-off between lowering the likelihood of perverse effects and maximising firms' incentives.

\section{Conclusion}

We have introduced the concept of environmental elasticity ${ }^{9}$ and showed how ecolabelling schemes can generate an adverse effect on the environment. The considered source of the 'perverse effect' differs from the previous literature, notably in introducing psychological considerations in the decision making process of consumers. The impact of immediate claims - such as 'less pollutant, less toxic per unit' influences the decision making process more than computed information about the individual or global overall environmental impact. Indeed, this complex computation consumes time, knowledge and expertise abilities. Moreover, from a public point of view, ecolabelling schemes can be more environmentally effective and economically efficient for certain categories than others. In other words, the selection of product categories matters. In some cases, ecolabelling schemes can need complementary devices to achieve their promises such as consumer education. Although we have focused our attention on ecolabelling schemes, the framework and the results are generic and can be easily applied to many other topics, such as light products, low-nicotine cigarettes ${ }^{10}$, low-alcohol beers or protective solar filters ${ }^{11}$. These products also provide a favourable field for empirical investigation, e.g. the evolution of consumption after the introduction of low-nicotine cigarettes and the combined effect of simultaneous quality and price changes. The main results have been derived under very simplifying assumptions. Many extensions can be analysed such as the combination of other related effects. Indeed, this paper has assumed consumers and firms behave somewhat rigidly by postulating identical consumers' preferences and the sole presence of the environmentally friendly product. All consumers do not react in the same way to the introduction of ecolabelling schemes. The co-existence of two identical products differing only by their environmental quality and two kinds of consumers unconcerned consumers and concerned ones - will make the model closer to the real world. Moreover, our reasoning is based on an informational policy instrument, which is market anchored and do not consider an eventual lifestyle change, e.g. substituting bike trips for car trips. Extending this setting and testing it empirically is a challenging topic for future research.

\footnotetext{
${ }^{9}$ In many cases related to credence goods, note that the elasticity is based on consumers' perception resulting more from the information tool (i.e. labelling) than the objective perception of the quality change.

${ }^{10}$ Despite mandatory warnings, it is broadly admitted that tobacco firms have tested and devised manipulative strategies to lower consumer risk perceptions and increase demand, e.g. by introducing low-nicotine cigarettes.
} 


\section{References}

Morris, J.; Scarlett, L., 1996, Buying Green: Consumers, Product Labels and the Environment, Policy

Study, 217, November, Reason Foundation, Los Angeles, CA.

Mattoo, A.; Singh, H., 1994, Eco-Labelling: Policy Considerations, Kyklos, 47(1) : 53-65.

Dosi, C.; Moretto, M., 2001, Is Eco-labelling a Reliable Environmental Policy Measure?, Environmental and Resource Economics, 18(1) : 113-127.

\footnotetext{
${ }^{11}$ Note that ecolabelling relates to the private provision of a public good, i.e. an environmental quality improvement while other labelling schemes (e.g. low nicotine cigarettes or protective solar filters) mainly relate to the provision of a private good. An intuitive implication is that properties described in the case of ecolabelling will be more emphasized in the case of labelling schemes promoting private benefits.
} 